\title{
How unusual was late 20th century EI Niño-Southern Oscillation (ENSO)? Assessing evidence from tree-ring, coral, ice-core and documentary palaeoarchives, A.D. 1525-2002
}

\author{
J. L. Gergis ${ }^{1}$ and A. M. Fowler ${ }^{2}$ \\ ${ }^{1}$ School of Biological, Earth and Environmental Sci., Univ. of New South Wales, Kensington, NSW 2052, Sydney, Australia \\ ${ }^{2}$ School of Geography and Environmental Science, University of Auckland, Private Bag 92019 Auckland, New Zealand
}

Received: 12 May 2005 - Revised: 25 January 2006 - Accepted: 26 January 2006 - Published: 1 February 2006

\begin{abstract}
Multiple proxy records (tree-ring, coral, ice and documentary) were examined to isolate ENSO signals associated with both phases of the phenomenon for the period A.D. 1525-2002. To avoid making large-scale inferences from single proxy analysis, regional signals were aggregated into a network of high-resolution records, revealing large-scale trends in the frequency, magnitude and duration of pre-instrumental ENSO using novel applications of percentile analysis. Here we use the newly introduced coupled ocean-atmosphere ENSO index (CEI) as a baseline for the calibration of proxy records. The reconstruction revealed 83 extreme or very strong ENSO episodes since A.D. 1525, expanding considerably on existing ENSO event chronologies. Significantly, excerpts of the most comprehensive list of La Niña events complied to date are presented, indicating peak activity during the 16th to mid 17th and 20th centuries. Although extreme events are seen throughout the 478year reconstruction, $43 \%$ of the extreme ENSO events noted since A.D. 1525 occur during the 20th century, with an obvious bias towards enhanced El Niño conditions in recent decades. Of the total number of extreme event years reconstructed, $30 \%$ of all reconstructed ENSO event years occur post-1940 alone suggesting that recent ENSO variability appears anomalous in the context of the past five centuries.
\end{abstract}

\section{Introduction}

El Niño-Southern Oscillation (ENSO) is associated with extreme weather events that influence climatic extremes such as drought, flooding, bushfires and tropical cyclone activity across vast areas of the Earth, often associated with large-scale socio-economic adversity. Despite impressive advances in the reconstruction of mean hemispheric and global temperatures of the past five centuries, relatively little atten-

Correspondence to: J. L. Gergis

(jgergis@gmail.com) tion has been devoted to assessing the long-term context of apparently anomalous ENSO behaviour witnessed in recent decades (Stahle et al., 1998; Crowley, 2000; Folland et al., 2001; Mann, 2003; D'Arrigo et al., 2005).

It is widely understood that instrumental time series $(<150$ years) are not long enough to ascertain if decadal-scale variability observed during the 20th century is atypical (Trenberth and Hoar, 1997; Allan and D'Arrigo, 1999; Dunbar and Cole, 1999; Fedorov and Philander, 2000). Consequently, multi-century palaeoclimate reconstructions derived from long proxy records, such as seasonally-annually resolved tree-ring, coral, ice or documentary records are sought to examine pre-instrumental patterns of ENSO variability (Jones and Mann, 2004).

Clarification of the definition of ENSO has long been recognised as an issue of practical relevance by CLIVAR (Climate Variability and Predictability), the largest initiative of the World Climate Research Programme (Trenberth, 1997). It is proposed here that an index of only component of ENSO is not ideal as it is only indicative of one physical aspect of the phenomenon, and, as such, is likely to incompletely resolve the wider interactions experienced in the coupled ocean-atmospheric system.

In an attempt describe more of the nature and evolution of ENSO conditions, Gergis and Fowler (2005a) devised the Coupled ENSO Index (CEI) to register synchronous oceanic (Niño 3.4 SST) and atmospheric (Southern Oscillation Index) anomalies for the instrumental period (1871-2003). Anomalies expressed in either Niño 3.4 SST or SOI indices (and therefore perhaps indicative of decoupled or out of phase behaviour) are maintained in the CEI, while fully coupled ocean-atmospheric anomalies result in an amplification of the index. Where previous studies have chosen to reconstruct the SOI or Niño region SSTs indices alone, here we use the newly introduced coupled ocean-atmosphere ENSO index as a baseline for the calibration of proxy records (Gergis and Fowler, 2005a). 
Table 1. Proxy data information of records used in this study. ${ }^{a}$ Berlage (1931), Murphy and Whetton (1989), Whetton and Rutherfurd (1994), Whetton et al. (1996); ${ }^{b}$ D'Arrigo et al. (1994), IGBP Pages/WDC-A for Paleoclimatology Contribution Series 1999-063; ${ }^{c}$ Fowler et al. (2000, 2004), Gergis et al. (2005b, 2005c); ${ }^{\mathrm{d}}$ Fenwick (2003); e Cleaveland et al. (2003), Stahle and Cleaveland (2002), IGBP Pages/WDC-A for Paleoclimatology Contribution Series 2002-004., Greybill (1994) IGBP Pages/WDC-A for Paleoclimatology Contribution Series 1994-003, Grissino-Mayer and Swetnam (1992) IGBP Pages/WDC-A for Paleoclimatology Contribution Series 1992-012, Dean (1993) IGBP Pages/WDC-A for Paleoclimatology Contribution Series 1993-021, Grow (2000) IGBP Pages/WDC-A for Paleoclimatology Contribution Series 2003-094; ${ }^{\mathrm{f}}$ Stahle et al. (1998), IGBP Pages/WDC-A for Paleoclimatology Contribution Series 2002-004; $\mathrm{g}$ Hendy et al. (1998), IGBP Pages/WDC-A for Paleoclimatology Contribution Series 2002-009; ${ }^{\mathrm{h}}$ Quinn et al. (1998), IGBP Pages/WDC-A for Paleoclimatology Contribution Series 1999-003; i Dunbar et al. (1994), IGBP Pages/WDC-A for Paleoclimatology Contribution Series 1994-013; ${ }^{j}$ Linsley et al. (2000), IGBP Pages/WDC-A for Paleoclimatology Contribution Series 2000-065; ${ }^{\mathrm{k}}$ Thompson et al. (1992) IGBP Pages/WDC-A for Paleoclimatology Contribution Series 1992-008; ${ }^{1}$ Quinn and Neal (1992), Ortlieb (2000); ${ }^{\mathrm{m}}$ Hassan (1981), Whetton and Rutherfurd (1994), Whetton et al. (1996); ${ }^{\mathrm{n}}$ Whetton and Rutherfurd (1994), Whetton et al. (1996); ${ }^{\circ}$ Wang and Zhao (1981), Whetton and Rutherfurd (1994), Whetton et al. (1996).

\begin{tabular}{|c|c|c|c|c|c|}
\hline Proxy Record & Dates (A.D.) & Data filter & ENSO Zone & Season & Climate Variable \\
\hline \multicolumn{6}{|l|}{ Tree-rings } \\
\hline Berlage Indonesian Teak ${ }^{a^{*}}$ & $1525-1929$ & 10-year Gaussian & West Pacific & SON & Total Ring Widths \\
\hline D'Arrigo Indonesian Teak ${ }^{\text {b* }}$ & 1841-1995 & 20-year Spline & West Pacific & SON & Total Ring Widths \\
\hline New Zealand Kauri ${ }^{c}$ & $1525-2002$ & 20-year Spline & West Pacific & SON & Total Ring Widths \\
\hline New Zealand Pink Pine ${ }^{d}$ & $1525-1998$ & 20-year Spline & West Pacific & JJA & Total Ring Widths \\
\hline Mexican Douglas Fir ${ }^{\mathrm{e}}$ & $1525-1998$ & 20-year Spline & East Pacific & DJF & Total Ring Widths \\
\hline SW USA Pinyon Pine ${ }^{f}$ & $1525-2000$ & 20-year Spline & East Pacific & DJF & Total Ring Widths \\
\hline \multicolumn{6}{|l|}{ Coral } \\
\hline Great Barrier Reef ${ }^{g}$ & 1612-1985 & 3-year Gaussian & South-west Pacific & DJF & Luminescence SSS \\
\hline New Caledonia ${ }^{h}$ & 1658-1992 & 3-year Gaussian & South-west Pacific & SON & $\delta \mathrm{O}^{18} \mathrm{SST}$ \\
\hline Galapagos Islands i & $1607-1982$ & 3-year Gaussian & East Pacific & DJF & $\delta \mathrm{O}^{18} \mathrm{SST}$ \\
\hline Rarotonga $^{j}$ & 1726-1997 & 3-year Gaussian & Central Pacific & DJF & $\mathrm{Sr} / \mathrm{Ca} \mathrm{SST}$ \\
\hline \multicolumn{6}{|l|}{ Ice } \\
\hline Quelccaya Ice Core k & $1525-1984$ & 3-year Gaussian & East Pacific & DJF & Net accumulation \\
\hline \multicolumn{6}{|l|}{ Historical Records } \\
\hline Quinn/Ortlieb' & $1525-1987$ & $\mathrm{~N} / \mathrm{A}$ & East Pacific & JJA & Rainfall \\
\hline Nile $^{m}$ & $1587-1984$ & 10-year Gaussian & North Africa Teleconnection & MAM & Rainfall \\
\hline India Drought ${ }^{n}$ & $1525-1984$ & $\mathrm{~N} / \mathrm{A}$ & South Asia Teleconnection & SON & Rainfall \\
\hline China $^{\circ}$ & 1525-1979 & 10-year Gaussian & North Asia Teleconnection & DJF & Rainfall \\
\hline
\end{tabular}

The CEI is of practical relevance to the ENSO community as it provides an amplitude preserving, composite index for the calibration of proxy records to simultaneously reconstruct both components of the ENSO system (Gergis and Fowler, 2005a). By maintaining both atmospheric and oceanic components of ENSO represented in the calibration process, it has been possible to resolve seasonal and spatial (teleconnection) characteristics of both decoupled and coupled ENSO episodes using existing palaeoarchives (Gergis, 2006; Braganza et al., 2006 ${ }^{1}$; Gergis and Fowler, $2006^{2}$ ).

This study reports the results derived from the integration of various regional signals from a variety of ENSO affected locations, to providing insight into the wider, global signature of ENSO events. The primary intention of this paper is to provide a list of very strong to extreme ENSO

\footnotetext{
${ }^{1}$ Braganza, K., Gergis, J., Risbey, J., and Fowler, A.: El NiñoSouthern Oscillation (ENSO) since A.D. 1525; evidence from treering, coral and ice-core records, in preparation, 2006.

${ }^{2}$ Gergis, J. and Fowler, A.: A history of ENSO events since A.D. 1525; implications for future climate change, in preparation, 2006.
}

events observed since A.D. 1525. To verify the occurrence of reconstructed existing ENSO event chronologies were consulted. Importantly, this paper introduces an excerpt of the most comprehensive listing of pre-instrumental La Niña events compiled to date which incorporates data from east and western Pacific centres-of-action (Gergis, 2006; Gergis and Fowler, 2006 ${ }^{2}$ ).

\section{Data and methodology}

2.1 Proxy selection and calibration with instrumental ENSO

An ENSO event is defined in the CEI as at least six months of simultaneous oceanic (Niño $3.4 \mathrm{SST}$ ) and atmospheric anomalies (SOI), with no more than two consecutive neutral months interrupting ENSO conditions. The seasonal CEI classifications, which maintain information about individual SST and SOI trends, were used to identify the presence and nature of any ENSO signal recorded within each proxy (Gergis and Fowler, 2005a). Proxy records used in this 
Table 2. Reconstructed El Niño events since A.D. 1525. Percentile analysis was used to classify the magnitude of events into extreme ( $>90$ th percentile) and very strong (70th-90th percentile). Excerpt taken from (Gergis, 2006; Gergis and Fowler, $2006^{2}$ ).

\begin{tabular}{|c|c|c|c|}
\hline $\begin{array}{l}\text { Reconstructed } \\
\text { Instrumental } \\
\text { EI Niño Events }\end{array}$ & $\begin{array}{c}\text { Reconstructed } \\
\text { Event Magnitude }\end{array}$ & $\begin{array}{l}\text { Reconstructed } \\
\text { Pre-Instrumental } \\
\text { El Niño Events }\end{array}$ & $\begin{array}{c}\text { Reconstructed } \\
\text { Event Magnitude }\end{array}$ \\
\hline $1871-2002$ & & $1870-1525$ & \\
\hline 2002 & E & 1868 & VS \\
\hline 1991-92 & vS & 1866 & vS \\
\hline 1987 & vS & 1853 & vS \\
\hline $1982-83$ & E & 1845 & vs \\
\hline $1941-42$ & E & 1806 & vs \\
\hline 1940 & vs & 1791 & vs \\
\hline 1926 & E & 1770 & vs \\
\hline 1918 & vS & 1737 & E \\
\hline $1912-15$ & vs & 1723 & $E$ \\
\hline 1905 & E & 1718 & E \\
\hline 1902 & VS & 1687 & vs \\
\hline 1900 & VS & 1660 & vs \\
\hline 1891 & vs & 1650 & E \\
\hline 1888 & vs & 1618 & vs \\
\hline \multirow[t]{8}{*}{1877} & vS & $1607-08$ & vS \\
\hline & & 1585 & vS \\
\hline & & 1574 & vs \\
\hline & & 1565 & vS \\
\hline & & 1559 & vs \\
\hline & & 1556 & vs \\
\hline & & 1544 & vS \\
\hline & & $1525-26$ & vs \\
\hline
\end{tabular}

study (Table 1) are largely based on published records from core ENSO and key teleconnection areas to ensure the use of high quality data (Allan et al., 1996). Attention was given to preserving geographical representation of signals from both eastern and western Pacific sites back to A.D. 1525. Note that in this paper, the season of proxy response listed in Table 1 relates to the strongest relationship identified with the CEI (Gergis and Fowler, 2005a) and does not assume any a priori seasonal response window based on previous analyses undertaken using other indices of ENSO.

Instead of calibrating proxies using commonly applied regression approaches, a percentile analysis was employed (Gergis, 2006; Gergis and Fowler, 2006 ${ }^{2}$ ). Since the technique is based upon the hierarchical ranking of all anomalies, there is no truncation of statistical outliers or loss of variance in subsequent applications. This is of significance as previous reconstructions have been known to underestimate the amplitude of ENSO events (Folland et al., 2001). Consequently, the novel application of this technique to ENSO analysis may have considerable implications for accurately deciphering the wealth of information contained within proxy archives (Gergis, 2006; Gergis and Fowler, $2006^{2}$ ).

\subsection{ENSO event magnitude}

Following extensive verification related to signal replication and comparison with existing chronologies of historical ENSO events (Gergis, 2006), a three (four) proxy threshold was used to define an El Niño (La Niña) event in a multiple proxy environment. To allow the skill of the proxy to be incorporated into the quantification of event magnitude, a quality adjusted magnitude (MQ) time series was devised (Gergis, 2006; Gergis and Fowler, 2006²).

Essentially, to define the intensity and quality of reconstructed events, a percentile analysis was performed on the MQ time series to isolate ( $>90$ th percentile) very strong (70th-90th percentile), strong (50th-70th), moderate (50th30 th) and weak events $(<30$ th) ENSO conditions. These percentile thresholds were determined by calibrating the multiproxy reconstructions to match conventional wisdom 
Table 3. Reconstructed La Niña events since A.D. 1525. Percentile analysis was used to classify the magnitude of events into extreme (>90th percentile) and very strong (70th-90th percentile). Excerpt taken from (Gergis, 2006; Gergis and Fowler, 2006 ${ }^{2}$ ).

\begin{tabular}{|c|c|c|c|}
\hline $\begin{array}{l}\text { Reconstructed } \\
\text { Instrumental } \\
\text { La Niña Events }\end{array}$ & $\begin{array}{l}\text { Reconstructed } \\
\text { Event Magnitude }\end{array}$ & $\begin{array}{l}\text { Reconstructed } \\
\text { Pre-Instrumental } \\
\text { La Niña Events }\end{array}$ & $\begin{array}{c}\text { Reconstructed } \\
\text { Event Magnitude }\end{array}$ \\
\hline $1871-2002$ & & $1870-1525$ & \\
\hline 1998 & $\mathrm{E}$ & 1863 & VS \\
\hline $1989-90$ & VS & $1860-61$ & vS \\
\hline 1974 & E & 1808 & VS \\
\hline 1971 & VS & 1805 & VS \\
\hline 1956 & VS & $1801-02$ & VS \\
\hline 1953 & E & 1788 & vS \\
\hline 1950 & E & 1752 & vs \\
\hline 1917 & VS & 1743 & VS \\
\hline $1909-10$ & VS & 1742 & $E$ \\
\hline 1894 & E & $1739-40$ & vS \\
\hline 1893 & VS & 1733 & VS \\
\hline 1887 & VS & 1696 & VS \\
\hline 1880 & VS & 1663 & vS \\
\hline 1879 & E & 1654 & VS \\
\hline 1873 & VS & 1645 & $E$ \\
\hline \multirow[t]{15}{*}{$1870-71$} & VS & 1641 & VS \\
\hline & & 1632 & $E$ \\
\hline & & 1631 & vS \\
\hline & & 1626 & VS \\
\hline & & $1623-24$ & VS \\
\hline & & 1600 & VS \\
\hline & & $1592-93$ & vs \\
\hline & & 1584 & vS \\
\hline & & $1572-73$ & $\mathrm{E}$ \\
\hline & & 1560 & vs \\
\hline & & 1548 & vS \\
\hline & & 1541 & vS \\
\hline & & 1533 & $E$ \\
\hline & & $1531-32$ & vS \\
\hline & & 1528 & $\mathrm{E}$ \\
\hline
\end{tabular}

as to what has historically been considered strong-extreme events in the instrumental period (post-1870) using previous research by Trenberth (1997) and the CEI (Gergis and Fowler, 2005a). These classes were then applied to the quality adjusted magnitude time series back to A.D. 1525. Here, only extreme and very strong ENSO events are selected for presentation from the entire ENSO event chronology (Gergis, 2006; Gergis and Fowler, 2006 ${ }^{2}$ ).

\subsection{Event verification}

To assist the selection of thresholds for the multiproxy event definition, the three and four proxy-threshold events were compared to past ENSO event lists published for the instrumental period (Rasmusson and Carpenter, 1983; Kiladis and Diaz, 1989; Quinn and Neal, 1992; Whetton and Rutherfurd, 1994; Mullan, 1995; Trenberth, 1997; Ortlieb, 2000; Allan et al., 2003). For the pre-instrumental period, two lists provided by the "Quinn record" (Ortlieb (2000) pre-1901 and Quinn and Neal (1992) for the post-1900 period) and Whetton and 
Table 4. Verification of reconstructed ENSO event frequency with existing long-term chronologies (Quinn and Neal, 1992; Whetton and Rutherfurd, 1994; Ortlieb, 2000). Here, El Niño (La Niña) event definition represents at least three (four) proxies replicating a single, regional ENSO signal. Note that total events for each sub-period includes all weak, moderate, strong, very strong and extreme magnitude events presented by Gergis (2006) and Gergis and Fowler $(2006)^{2}$, rather than the limited very-strong to extreme events presented in Tables 2 and 3 .

\begin{tabular}{lccc}
\hline ENSO Event Lists & $\begin{array}{c}\text { Instrumental } \\
\text { Event Capture } \\
(\mathbf{1 8 7 1 - 2 0 0 2 )}\end{array}$ & $\begin{array}{c}\text { Pre-Instrumental } \\
\text { Event Capture } \\
(\mathbf{1 5 2 5 - 1 8 7 0 )}\end{array}$ & $\begin{array}{c}\text { Total Event } \\
\text { Capture } \\
(\mathbf{1 5 2 5 - 2 0 0 2 )}\end{array}$ \\
\hline EI Niño & 27 & 65 & 92 \\
3+ proxy replication & 29 & 80 & 109 \\
Quinn \& Ortlieb & 16 & 23 & 39 \\
Whetton and Rutherfurd & & & 82 \\
La Niña & 21 & 61 & - \\
4+ proxy replication & - & - & 10 \\
Quinn and Ortlieb & 4 & 6 & \\
Whetton and Rutherfurd & & & \\
\hline
\end{tabular}

Rutherford (1994) were used. Only comparisons with the long-term ENSO chronologies are presented to avoid covering material beyond the scope of this summary paper.

\section{Results}

From Table 2, a total of 37 very-strong to extreme El Niño were reconstructed since A.D. 1525. Nine events were classifies as extreme, including four well known events of the 20 th century $(2002,1982-83,1941-42,1926,1905)$. The 18 th century contained a further three events $(1737,1723$, 1718) while only one extreme El Niño event of A.D. 1650 was recorded during the 16th and 17th centuries. The 20th century represents the peak of El Niño activity, when twelve events were classed as either very strong or extreme (Table 2).

Table 3 presents the results for the La Niña phase reconstruction. A total of 46 events were reconstructed, twelve of these classified as extreme. Four extreme La Niña events $(1998,1974,1953,1950)$ were reconstructed during the 20th century. The pre-instrumental period indicates relatively more La Niña activity with 6(24) extreme (very strong) events compared to 4(18) extreme (very strong) events from the El Niño reconstruction. Considerable La Niña activity is indicated during the 16th to mid 17th centuries when five extreme events are reconstructed. The obvious trend towards increased La Niña activity over the 20th century is also evident from Table 3.

Table 4 shows the event frequency characterisitcs of the two primary long-term ENSO event lists of "Quinn" (Quinn and Neal, 1992; Ortlieb, 2000) and Whetton and Rutherfurd (1994) and the multiproxy event lists presented here. There is a high degree of similarity between the Quinn and Ortlieb chronologies and the use of three proxies for El Niño event definition. The additional 16 events not included in the multiproxy event lists may indicate El Niño conditions that may have only been regional in nature. Events from the multiproxy reconstructions have a longer duration than a number of the events indicated in the Quinn records (not shown), which may reflect the impact of calibrating proxies using the CEI which allowed lead/lag signatures associated with decoupled events to be resolved. Consequently, the results may be a sign of larger-scale patterns of ENSO events, rather than the response of one (East Pacific) teleconnection region.

Verification of La Niña events was substantially more difficult due to the lack of coverage in the Quinn records and a total of ten events noted by Whetton and Rutherfurd (1994). The year A.D. 1906 is the only La Niña event not present in the four proxy La Niña chronologies, however, the 1826 La Niña noted by Whetton and Rutherfurd (1994) is only detectable using a three-proxy threshold (not shown). Since there were minor differences in the event capture characteristics of the three and four-proxy event lists, a four proxy threshold for La Niña event definition was considered to be slightly more conservative.

\section{Discussion}

Verification revealed that a three (four) proxy minimum for El Niño (La Niña) event definition compared well with the two primary long-term ENSO event list of "Quinn" (Quinn and Neal, 1992; Ortlieb, 2000) and Whetton and Rutherfurd (1994). This study provides substantial replication and extension of the events reported by previous research. In particular, the results of Table 3 represent excerpts of the most comprehensive list of La Niña events complied to date (Gergis, 2006; Gergis and Fowler, 2006 ${ }^{2}$ ).

Here, a total of 37 (46) extreme or very strong El Niño (La Niña) episodes since A.D. 1525. Enhanced ENSO activity of the 19th and 20th century is apparent from the ENSO events presented in Tables 2 and 3. From the reconstruction introduced in this paper, it is apparent that La Niña activity has 
fluctuated considerably through time, with peaks in the 16th to mid 17 th and 20th centuries. The 20th century stands out as the peak period of El Niño activity. In total, $43 \%$ of the extreme events noted since A.D. 1525 occur during the 20th century, with a bias towards enhanced El Niño conditions (Table 2). Strikingly, the post-1940 period alone accounts for $30 \%$ of the total extreme ENSO event years reconstructed over the past five centuries.

\section{Conclusions}

This paper identified a total of 83 extreme and very strong ENSO events since A.D. 1525, many of which were verified using available long-term ENSO event chronologies. In total, $43 \%$ of the extreme events noted since A.D. 1525 occur during the 20th century, with an obvious bias towards enhanced El Niño conditions. 30\% of all extreme ENSO years occur post-1940 suggesting that recent ENSO variability may be anomalous in the context of the past five centuries.

An considerably expanded analysis of the nature, magnitude and frequency of pre-observational ENSO events is currently underway to further clarify changes in past ENSO behaviour (Gergis, 2006; Braganza et al., 2006 ${ }^{1}$; Gergis and Fowler, $2006^{2}$ ). Given the large-scale socio-economic impacts of ENSO events, future investigation into the possible impact an increasingly anthropogenically-warmed world will have on ENSO behaviour is vital.

Acknowledgements. J. L. Gergis thanks the European Geophysical Union and the International Research Center on El Niño (CIFFEN) for financial assistance to participate in the 1st International Alexander Von Humboldt Conference on the El Niño phenomenon and its global impact. Many thanks to P. Whetton (CSIRO) and I. Rutherfurd (University of Melbourne) for Nile Flood Record, Berlage Teak Chronology, North China Rainfall data, E. Hendy (Lamont Doherty Earth Observatory) for Great Barrier Reef coral luminescence record, P. Fenwick (Lincoln University, New Zealand) for Pink Pine tree-ring data, B. Bauer and C. Woodhouse (World Data Center for Paleoclimatology/National Climatic Data Center Paleoclimatology Branch) for data acquisition and assistance. J. L. Gergis was supported at UNSW by an Australian Postgraduate Award.

Edited by: P. Fabian and J. L. Santos

Reviewed by: L. Ortlieb and another anonymous referee

\section{References}

Allan, R. and D'Arrigo, R.: "Persistent" ENSO sequences: how unusual was the 1990-1995 El Niño?, The Holocene, 9(1), 101118, 1999.

Allan, R., Lindsay, J., and Parker, D.: El Niño Southern Oscillation and climate variability, Melbourne, Australia, CSIRO, 1996.

Allan, R., Reason, C., Lindesay, J., and Ansell, T.: Protracted ENSO episodes and their impacts in the Indian Ocean region, Deep Sea Res. II, 50(12-13), 2331-2347, 2003.

Berlage, H.: On the relationship between thickness of tree rings of Djati and rainfall on Java, Tectona, 24, 939-953, 1931.
Cleaveland, M., Stahle, D., Therrell, M., Villanueva-Diaz, J., and Burns, B.: Tree-ring Reconstructed Winter Precipitation and Tropical Teleconnections in Durango, Mexico, Climatic Change, 59, 369-388, 2003.

Crowley, T.: Causes of Climate Change over the Past 1,000 years, Science, 289, 270-277, 2000.

D’ Arrigo, R., Cook, E., Wilson, R., Allan, R., and Mann, M.: On the variability of ENSO over the past six centuries, Geophys. Res. Lett., 32(L03711), 1-4, 2005.

D' Arrigo, R., Jacoby, G., and Krusic, P.: Progress in Dendroclimatic Studies in Indonesia, Terrestrial, Atmospheric and Oceanographic Sciences, 5, 349-363, 1994.

Dunbar, R. and Cole, J.: Annual Records of Tropical Systems (ARTS); Recommendations for Research, Geneva, Switzerland, IGBP Science Series, 1999.

Fedorov, A. and Philander, G.: Is El Niño changing?, Science, 288, 1997-2002, 2000.

Fenwick, P.: Reconstruction of past climates using pink pine (Halocarpus biformus) tree-ring chronologies, Christchurch, New Zealand, Soil Plant and Ecological Sciences, Linclon University, 2003.

Folland, C., Karl, T., Christy, J., Clarke, R., Gruza, G., Jouzel, J., Mann, M., Oerlemans, J., Salinger, M., and Wang, S.: Observed Climate Variability and Change, in: Climate Change 2001: The Scientific Basis, Contribution of Working Group 1 to the Third Assessment Report of the Intergovernmental Panel on Climate Change, edited by: Houghton, J., Ding, Y., Griggset, D., et al., United Kingdom and New York, Cambridge University Press, 2001.

Fowler, A., Boswijk, G., and Ogden, J.: Tree-ring studies on Agathis australis (Kauri): a synthesis of development work on Late Holocene chronologies, Tree Ring Research, 60(1), 15-29, 2004.

Fowler, A., Palmer, J., Salinger, J., and Ogden, J.: Dendroclimatic interpretation of tree-rings in Agathis australis (Kauri) 2; Evidence of a significant relationship with ENSO, Journal of Royal Society of New Zealand, 30(3), 277-292 2000.

Gergis, J.: Reconstructing El Niño-Southern Oscillation; evidence from tree-ring, coral, ice and documentary palaeoarchives, A.D. 1525-2002. PhD Thesis, School of Biological, Earth and Environmental Sciences, Sydney, University of New South Wales, 2006.

Gergis, J. and Fowler, A.: Classification of synchronous oceanic and atmospheric El Niño-Southern Oscillation (ENSO) events for palaeoclimate reconstruction, Int. J. Climatol., 25, 15411565, 2005a.

Gergis, J., Boswijk, G., and Fowler, A.: An update of modern Northland Kauri (Agathis australis) tree-ring chronologies 1: Puketi State Forest, New Zealand tree-ring Site Report No. 19, School of Geography and Environmental Science Working Paper 29, University of Auckland, New Zealand, 2005b.

Gergis, J., Boswijk, G., and Fowler, A.: An update of modern Northland Kauri (Agathis australis) tree-ring chronologies 2: Trounson Kauri Park, New Zealand tree-ring Site Report No. 20, School of Geography and Environmental Science Working Paper 30, University of Auckland, New Zealand, 2005c.

Hassan, F.: Historical Nile Floods and Their Implications for Climatic Change, Science, 212, 1142-1145, 1981.

Jones, P. and Mann, M.: Climate over past millenia, Rev. Geophys., 42, 1-42, 2004. 
Kiladis, G. and Diaz, H.: Global climatic anomalies associated with extremes in the Southern Oscillation, J. Climate, 2, 1069-1090, 1989.

Mann, M.: On Past Temperatures and Anomalous Late-20th Century Warmth, Eos, 84(27), 1-3, 2003.

Mullan, A.: On the linearity and stability of Southern Oscillationclimate relationships for New Zealand, Int. J. Climatol., 15, 1365-1386, 1995.

Murphy, J. and Whetton, P.: A re-analysis of a tree-ring chronology from Java, Proceedings of the Koninklijke Nederlandse Akademie van Wetenschappen (Dendrochronology), Proceedings B, 92(3), 241-257, 1989.

Ortlieb, L.: The documentary historical record of El Niño events in Peru: An update of the Quinn record (sixteenth through nineteenth centuries), in: El Niño and the Southern Oscillation: Variability, Global and Regional Impacts, edited by: Diaz, H. and Markgraf, V., Cambridge, Cambridge University Press, 207-295, 2000.

Quinn, W. and Neal, V.: The historical record of El Niño events, in: Climate Since A.D. 1500, edited by: Bradley, R. and Jones, P., London, Routledge, 623-648, 1992.
Rasmusson, E. and Carpenter, T.: The relationship between eastern equatorial Pacific sea surface temperatures and rainfall over India and Sri Lanka, Mon. Wea. Rev., 111, 517-528, 1983.

Stahle, D., D’Arrigo, R., Krusic, P., Cleaveland, M., Cook, E., Allan, R., Cole, J., Dunbar, R., Therrell, M., Gay, D., Moore, M., Stokes, M., Burns, B., Villanueva-Diaz, J., and Thompson, L.: Experimental dendroclimatic reconstruction of the Southern Oscillation, Bull. Amer. Meteor. Soc., 79(10), 2137-2152.

Trenberth, K.: The Definition of El Niño, Bull. Amer. Meteor. Soc., 78(12), 2771-2777, 1997.

Trenberth, K. and Hoar, T.: El Niño and climate change, Geophys. Res. Lett., 24(23), 3057-3060 1997.

Wang, S. and Zhao, Z.: Droughts and floods in China, 1470-1979, in: Climate and History, edited by: Wigley, T., Ingrasham, M., and Farmer, G., Cambridge University Press, 171-288, 1981.

Whetton, P., Allan, R., and Rutherfurd, I.: Historical ENSO teleconnections in the Eastern Hemisphere: comparisons with latest El Niño series of Quinn, Clim. Change, 32, 103-109, 1996.

Whetton, P. and Rutherfurd, I.: Historical ENSO teleconnections in the Eastern Hemisphere, Clim. Change, 28, 221-253, 1994. 